\title{
THE TOXICITY OF EXTRACTS WITH BIMETALLIC NANOPARTICLES ON FERNS SPORES GERMINATION
}

\author{
Liliana Cristina Soare ${ }^{1}$, Irina Fierăscu ${ }^{2}$, Radu-Claudiu Fierăscu ${ }^{2}$, Codruța Mihaela Dobrescu ${ }^{1 *}$, \\ Anca Nicoleta Șuțan ${ }^{1}$, Oana-Alexandra Drăghiceanu ${ }^{1}$ \\ ${ }^{1}$ University of Pitești, Târgu din Vale Street, 110040, Pitești, Romania \\ ${ }^{2}$ National Institute for Research \&Development in Chemistry and Petrochemistry - ICECHIM Bucharest, Romania
}

\begin{abstract}
Plants based synthesis of Ag and Au nanoparticles represent one of the most important focus of researchers due to their applications and catalytic activities. We utilized various techniques to obtain extracts with bimetallic nanoparticles from Asplenium scolopendrium leaves; we tested the following variants: $M$ - microwave extract, $M$ NP - microwave extract with nanoparticles Au-Ag, C - extract obtained in the oven, C NP - extract obtained in the oven with nanoparticles $\mathrm{Au}-\mathrm{Ag}, \mathrm{H}$ - hydroalcoholic solution; for each extract were made 2 dilutions: 1:10 and 1:100.

The germinative percent was used to quantify the effect of the extracts with/without bimetallic nanoparticles on Asplenium scolopendrium and Dryopteris filix-mas spores. In the variants with bimetallic nanoparticles, regardless species, dilution or obtaining technique, after 1 week no germination was recorded and after one month the situation was the same. Also, no germination was observed in the variants without bimetallic nanoparticles with 1:10 dilution. In both species, at 1:100 dilution, the variants with the extract obtained using microwave technique (without nanoparticles) recorded a higher germinative percent than the other variants with extract.
\end{abstract}

Keywords: bimetallic extracts, ferns, spores.

\section{INTRODUCTION}

Nanotechnology is a rapidly developing industry (Salman Khan et al., 2016) which has a significant influence on society, economy and environment. (Zaka and Abbasi, 2016). Singh et al. (2011) define nanoparticles (NPs) as small objects that behave as a whole unit regarding transport and properties. The classification of nanoparticles can be done upon their morphology, size, chemical properties etc. Based on physical and chemical characteristics Khan et al. (2019) classify nanoparticles in 6 categories: Carbon-based NPs, Metal NPs, Ceramics NPs, Semiconductor NPs, Polymeric NPs, Lipid-based NPs. Metallic nanoparticles have uniform size and their dimensions (length, width, thicknes) are within the range 1-100 nm (Harish Kumar et al., 2018); they have unique catalitic, electronic, optical and structural properties (Roopan et al., 2014). For a long time metal nanoparticles have been synthetized using physical and chemical methods (Parsons et al., 2007) but, in the last years, green technology became more attractive (Mohamad et al., 2013). Biological synthesis of nanoparticles is: more energy efficient and able to eliminate the use of dangerous chemicals (Mohamad et al., 2013), relatively simple, cheap (Kulkarni and Muddapur, 2014), ecofriendly and nontoxic. Biosynthesis of nanoparticles using plants systems is under 


\section{Current Trends in Natural Sciences}

Vol. 9, Issue 18, pp. 133-138, 2020

https://doi.org/10.47068/ctns.2020.v9i18.018

Current Trends in Natural Sciences (on-line)

ISSN: 2284-953X

Current Trends in Natural Sciences (CD-Rom)

ISSN: 2284-9521

ISSN-L: 2284-9521

ISSN-L: 2284-9521

extensive research (Dauthal and Mukhopadhyay, 2016), plants extracts are preferred over microbial sources because they don't need sterile conditions (Salunke et al., 2014).

Plants based synthesis of $\mathrm{Ag}$ and $\mathrm{Au}$ nanoparticles represent one of the most important focus of researchers due to their applications and catalytic activities. The Au and Ag metals were used in chronic disease, for enhancing the health and metabolic functions of the human body (Kuppusamy et al., 2017).

Venkatesan and Santhanalakshmi (2012) observed that bimetallic nanoparticles (AuAg) were more efficient than monometallic nanoparticles ( $\mathrm{Au}$ and $\mathrm{Ag}$ ) in terms of catalytic activity in the oxidation process of amino acids. Because AuNPs and AgNPs are produced in increasing amounts (Zhan et al., 2019) an important issue is to evaluate their potential toxicity (Barrena et al., 2009).Generally, in biological studies bimetallic nanoparticles are used as antimicrobial and antioxidant agents but in this study we tried a new approach: to determinate the effect of this nanoparticles on the most susceptible stage in ferns development.

\section{MATERIALS AND METHODS}

Mature leaves from Asplenium scolopendrium (As) and Dryopteris filix-mas (Dfm) were collected from several individuals in different sites (Vâlsan Valley) in order to ensure spores genetic diversity. After releasing the spores in the sporangia, there followed their collecting and preserving in a refrigerator at $4^{\circ} \mathrm{C}$. The extracts were obtained from Asplenium scolopendrium leaves which also were collected from Vâlsan Valley. A mixture for extraction (distilled water:ethanol - 1:1) was poured over the chopped leaves and than the solution was kept for 25 minutes at $72^{\circ} \mathrm{C}$ at microwave (M), and at the same temperature in the oven for 2 and a half hours (C). We utilized various techniques (microwave and the oven) to obtain the extracts because we also wanted to study the effect of obtaining technique extract on the spore germination. Some variants contained, beside the extracts, bimetallic nanoparticles $\mathrm{Au}-\mathrm{Ag}$ (M NP; C NP). We used $\mathrm{AgNO}_{3}$ and $\mathrm{HAuCl}_{4}$ in proportion 1:1. Variants with hydroalcoholic solution were also tested $(\mathrm{H})$. We exposed the spores of the ferns to two different concentration of each extract/solution (1:10, 1:100). For Control the germination media was constituted by distilled water (Table 1).

Table 1. Tested variants

\begin{tabular}{|c|c|c|}
\hline Variants & Contain & Dilution \\
\hline Control & distilled water & - \\
\hline M 1:10 & \multirow{2}{*}{ microwave extract } & $1: 10$ \\
\hline M 1:100 & & $1: 100$ \\
\hline M NP 1:10 & \multirow{2}{*}{ microwave extract with bimetallic nanoparticles (Au-Ag) } & $1: 10$ \\
\hline M NP 1:100 & & $1: 100$ \\
\hline C1:10 & \multirow{2}{*}{ extract obtained in the oven } & $1: 10$ \\
\hline C 1:100 & & $1: 100$ \\
\hline C NP 1:10 & \multirow{2}{*}{ extract obtained in the oven with bimetallic nanoparticles (Au-Ag) } & $1: 10$ \\
\hline C NP 1:100 & & $1: 100$ \\
\hline H 1:10 & \multirow[t]{2}{*}{ hydroalcoholic solution } & $1: 10$ \\
\hline H 1:100 & & $1: 100$ \\
\hline
\end{tabular}

The culture vessels were kept in growth chamber with constant humidity and illumination. The germinative percent was used to quantify the effect of the extracts with/without bimetallic 
nanoparticles on Asplenium scolopendrium (As) and Dryopteris filix-mas spores (Dfm); for obtaining an overview there were made multiple comparations (with Duncan test) between the variants with extracts and control.

\section{RESULTS AND DISCUSSIONS}

In the variants with bimetallic nanoparticles, regardless species, dilution or obtaining technique, after 1 week no germination was recorded and after one month the situation was the same (Fig. 34). Also, no germination was observed in the variants without bimetallic nanoparticles with 1:10 dilution (Fig.5-6). In both species, at 1:100 dilution, the variants with the extract obtained using microwave technique (without nanoparticles) (Fig. 8) recorded a higher germinative percent than the variants with the extract obtained in the oven (Fig. 1-2, Fig. 7). We can conclude that the microwave technique is more efficient because we had better results using it and the quantity of extract obtained was bigger than that which resulted from the oven. Hydroalcoholic solution inhibited spore germination: in the variants with 1:10 dilution the spores didn't germinate (Fig. 9) while at 1:100 dilution (Fig. 10). the germinative percent was significant smaller than control (Fig. $1-2)$.

No germination was also reported by Soare et al. (2019) after testing Asplenium scolopendrium and Dryopteris filix-mas extracts with AgNPs on Dryopteris filix-mas and Dryopteris affinis spores.

The cytotoxicity of AuNPs varies upon nanoparticles size, shape and surface, aggregation, interaction with biological molecules, cell type and cellular media (Caballero-Díaz and Valcárcel, 2014). AuNPs can induce ROS production which damage DNA and determinate cell death (Jia et al., 2017)

Phytotoxicity of AuNPs $\left(6 \times 10^{-6} \mathrm{M}-1.8 \times 10^{-5} \mathrm{M}\right.$ concentration $)$ was observed in the experiment made by Ostroumov et al (2014) after long term exposure (17 day and more) in Ceratophyllum demersum.

Increases in cell death, hydrogen peroxide formation and lipid peroxidation in Oryza sativa roots and shoots were observed by Ndeh et al. (2017) after AuNPs exposure, but these increases weren`t statistically significant.

It was demonstrated that AgNPs could affect seed germination and root growth, reduce biomass and leaf area, decline transpiration rate and alterate the hormone, disrupt the synthesis of chlorophyll and reduce nutrient uptake (Yan and Chen, 2019).

In Arabidopsis thaliana the AgNPs exposure had a significant inhibition on: root elongation in a dose-dependent manner and on chlorophyll content (Qian et al., 2013).

Root and shoot fresh mass and length of Brassica sp. seedling descreased in the variants with AgNPs compared with Control. The reduction of growth parameters might be linked with the reduction in photosynthetic performance (Vishwakarma et al., 2017).

The addition of Ag nanoparticles to the nutrient medium decreased seed germination and the growth of shoots and root length in Vicia faba (Abd-Alla et al. 2016) while the addition of Au nanoparticles increased the length of stem and root in Arabidopsis thaliana (Kumar et al. 2013).

Salman Khan et al. (2016) studied the monometallic (Ag, $\mathrm{Au}, \mathrm{Cu}$ ) and bimetallic (Ag $\mathrm{Cu}(1: 3), \mathrm{Ag}$ $\mathrm{Cu}$ (3:1), $\mathrm{Au} \mathrm{Cu}$ (1:3), $\mathrm{Au} \mathrm{Cu}$ (3:1), Ag Au (1:3), Ag Au (3:1)) nanoparticles effect on Silybum marianum. Seed germination was affected and increased significantly upon treatment. 


\section{Current Trends in Natural Sciences}

Vol. 9, Issue 18, pp. 133-138, 2020

https://doi.org/10.47068/ctns.2020.v9i18.018

Current Trends in Natural Sciences (on-line)

ISSN: 2284-953X

Current Trends in Natural Sciences (CD-Rom)

ISSN: 2284-9521

ISSN-L: 2284-9521 ISSN-L: 2284-9521

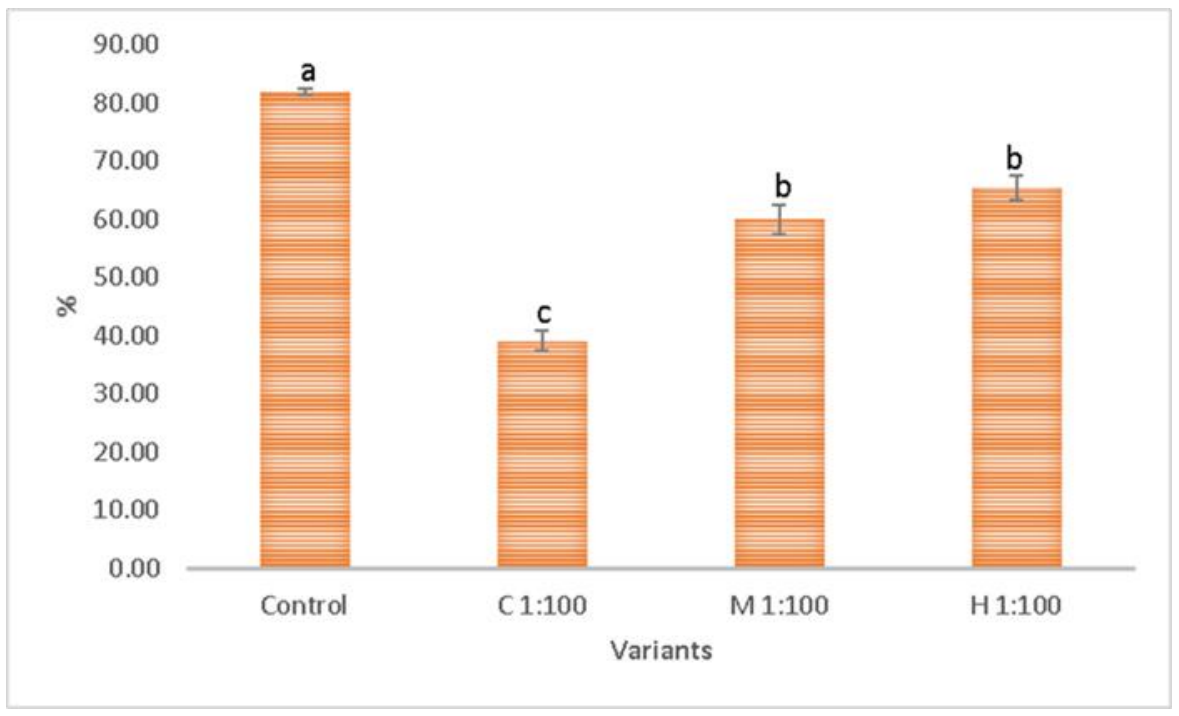

Figure 1. The influence of extracts on spore germination in Dryopteris filix-mas-after 1 week

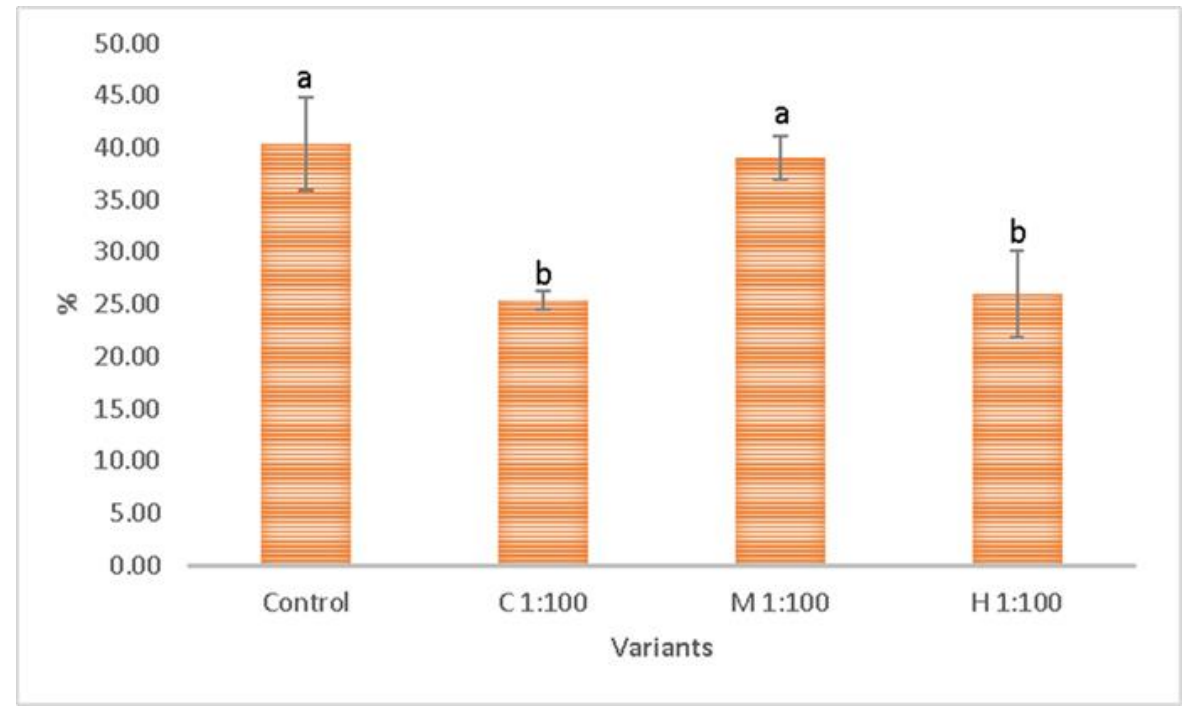

Figure 2. The influence of extracts on spore germination in Asplenium scolopendrium-after 1 week
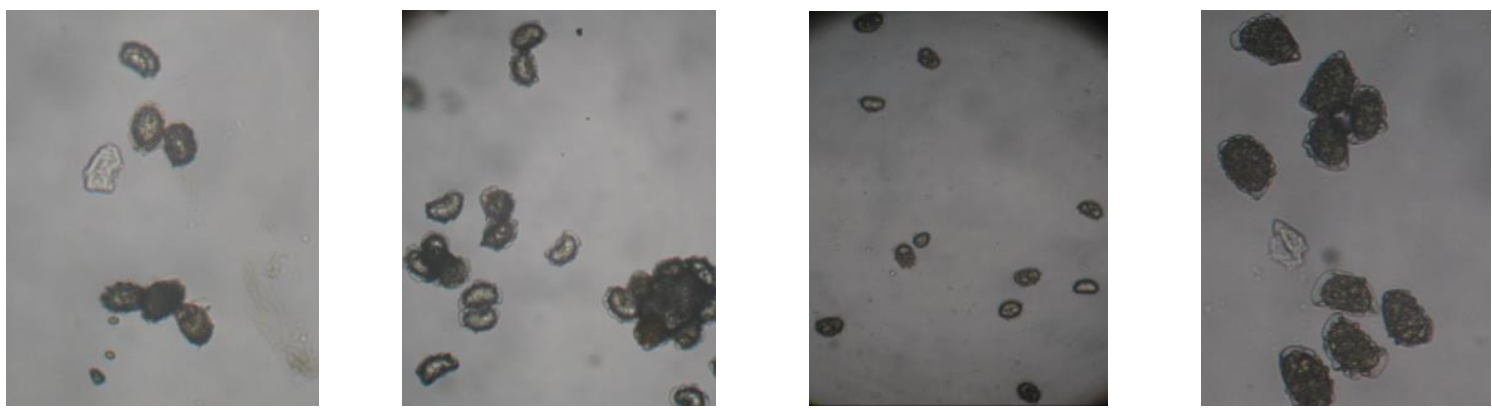

Figure 3. As C NP 1:100 Figure 4. Dfm M NP 1:100

Figure 5. As M 1:10

Figure 6. Dfm C 1:10 


\section{Current Trends in Natural Sciences}

Vol. 9, Issue 18, pp. 133-138, 2020

https://doi.org/10.47068/ctns.2020.v9i18.018

Current Trends in Natural Sciences (on-line)

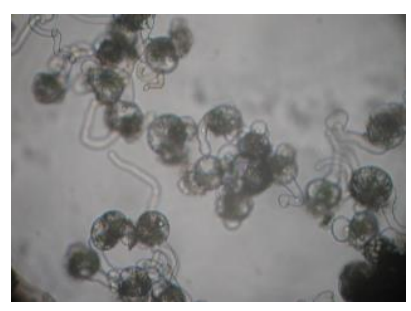

Figure 7. Dfm C 1:100

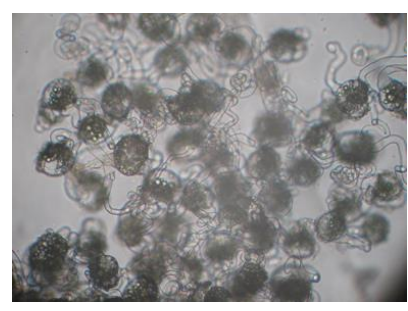

Figure 8. Dfm M 1:100

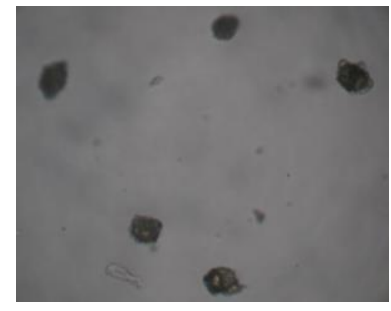

Figure 9. Dfm H 1:10

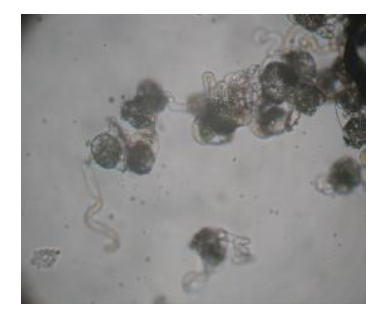

Figure 10. Dfm H 1:100

Legend: As - Asplenium scolopendrium; Dfm - Dryopteris filix-mas; The pictures were made after 1 month of exposure (x100)

\section{CONCLUSIONS}

The Asplenium scolopendrium extracts with bimetallic nanoparticles had a negative influence on spores by inhibiting the germination in both ferns species. A similar reaction was observed at the smallest (1:10) dilution in the hydroalcoholic variant and in the variants without nanoparticles.

\section{ACKNOWLEDGEMENTS}

This work was supported by a grant of the Romanian Ministery of Research and Innovation, CCCDIUEFISCDI, project number PN-III-P1-1.2-PCCDI-2017-0332"/Project 3, contract 6PCCDI/2018, within PNCDI II.

\section{REFERENCES}

Abd-Alla, M.H., Nafady, N.A., Khalaf, D.M. (2016). Assessment of silver nanoparticles contamination on faba beanRhizobium leguminosarum bv. viciae-Glomus aggregatum symbiosis: Implications for induction of autophagy process in root nodule. Agriculture, Ecosystems \& Environment, 218, 163-177. doi:10.1016/j.agee.2015.11.022

Barrena, R., Casals, E., Colón, J., Font, X., Sánchez, A., Puntes, V. (2009). Evaluation of the ecotoxicity of model nanoparticles. Chemosphere, 75(7), 850-857. doi:10.1016/j.chemosphere.2009.01.078

Caballero-Díaz, E., Valcárcel, M. (2014). Toxicity of gold nanoparticles. Comprehensive Analytical Chemistry, 207254. doi:10.1016/b978-0-444-63285-2.00005-

Dauthal, P., Mukhopadhyay, M. (2016). Noble metal nanoparticles: plant-mediated synthesis, mechanistic aspects of synthesis, and applications. Industrial \& Engineering chemistry research, 55(36), 95579577. doi:10.1021/acs.iecr.6b00861

Harish Kumar, K, Venkatesh N., Bhowmik H., Kuila, A. (2018) Metallic nanoparticle: a review. Biomedical Journal of Scientific \& Technical Research, 4(2), 3765-3775 DOI: 10.26717/BJSTR.2018.04.001011

Jia, Y.-P., Ma, B.-Y., Wei, X.-W., Qian, Z.-Y. (2017). The in vitro and in vivo toxicity of gold nanoparticles. Chinese Chemical Letters, 28(4), 691-702. doi:10.1016/j.cclet.2017.01.021

Khan, I., Saeed, K., Khan, I. (2019). Nanoparticles: properties, applications and toxicities. Arabian Journal of Chemistry, 12(7), 908-931. doi:10.1016/j.arabjc.2017.05.011

Kulkarni, N., Muddapur, U. (2014). Biosynthesis of Metal Nanoparticles: A Review. Journal of Nanotechnology, 18. doi:10.1155/2014/510246

Kumar, V., Guleria, P., Kumar, V., Yadav, S.K. (2013). Gold nanoparticle exposure induces growth and yield enhancement in Arabidopsis thaliana. Science of The Total Environment, 461-462, doi:10.1016/j.scitotenv.2013.05.018

Kuppusamy, P., Ilavenil, S., Srigopalram, S., Kim, D.H., Govindan, N., Maniam, G.P., Yusoff M.M., Choi, K.C. (2017). Synthesis of bimetallic nanoparticles (Au-Ag Alloy) using Commelina nudiflora $\mathrm{L}$. plant extract and study its on oral pathogenic bacteria. Journal of Inorganic and Organometallic Polymers and Materials, 27(2), 562-568. doi:10.1007/s10904-017-0498-8 
Mohamad, N.A.N., Arham, N.A., Jai, J., Hadi, A. (2013). Plant extract as reducing agent in synthesis of metallic nanoparticles: A Review. Advanced Materials Research, 832, 350-355. doi:10.4028/www.scientific.net/amr.832.350

Ndeh, N.T., Maensiri, S., Maensiri, D. (2017). The effect of green synthesized gold nanoparticles on rice germination and roots. Advances in Natural Sciences: Nanoscience and Nanotechnology, 8(3), 035008. doi:10.1088/20436254/aa724a

Ostroumov, S.A., Poklonov, V.A., Kotelevtsev, S.V., Orlov, S.N. (2014). Toxicity of gold nanoparticles for plants in experimental aquatic system. Moscow University Biological Sciences Bulletin, 69(3), 108-112. doi: $10.3103 / \mathrm{s} 0096392514030080$

Parsons, J.G., Peralta-Videa, J.R., Gardea-Torresdey, J.L. (2007). Use of plants in biotechnology: Synthesis of metal nanoparticles by inactivated plant tissues, plant extracts, and living plants. Developments in Environmental Science, 463-485. doi:10.1016/s1474-8177(07)05021-8

Qian, H., Peng, X., Han, X., Ren, J., Sun, L., Fu, Z. (2013). Comparison of the toxicity of silver nanoparticles and silver ions on the growth of terrestrial plant model Arabidopsis thaliana. Journal of Environmental Sciences, 25(9), 1947-1956. doi:10.1016/s1001-0742(12)60301-5

Roopan, S.M., Surendra, T.V., Elango, G., Kumar, S.H.S. (2014). Biosynthetic trends and future aspects of bimetallic nanoparticles and its medicinal applications. Applied Microbiology and Biotechnology, 98(12), 52895300. doi:10.1007/s00253-014-5736-1

Salman Khan, M., Zaka, M., Haider Abbasi, B., Rahman, L., Shah, A. (2016). Seed germination and biochemical profile of Silybum marianum exposed to monometallic and bimetallic alloy nanoparticles. IET Nanobiotechnology, 10(6), 359-366. doi:10.1049/iet-nbt.2015.0050

Salunke, G.R., Ghosh, S.., Santosh Kumar, RJ., Khade, S., Vashisth, P., Kale, T., Chopade, S., Pruthi, V., Kundu, G., Bellare, J.R., Chopade, B.A.. (2014) Rapid efficient synthesis and characterization of silver, gold, and bimetallic nanoparticles from the medicinal plant Plumbago zeylanica and their application in biofilm control. Int J Nanomedicine, 27(9), 2635-53. Doi: 10.2147/Ijn.S59834.

Singh, M., Manikandan S., Kumaraguru A.K. (2011) Nanoparticles: A new technology with wide applications. Research Journal of Nanoscience and Nanotechnology, 1: 1-11. Doi 10.3923/rjnn.2011.1.11

Soare, L.C., Fierăscu, I., Fierăscu, R.C., Dobrescu, C.M., Păunescu, A., Șuțan, A.N, Drăghiceanu, O.A. (2019). The germination of spores and gametophyte development in ferns under extracts influence. Proceedings, 29(1), 25. doi:10.3390/proceedings2019029025

Venkatesan, P., Santhanalakshmi, J. (2012). kinetics of oxidation of 1-leucine by mono- and bimetallic gold and silver nanoparticles in hydrogen peroxide solution. Chinese Journal of Catalysis, 33(7-8), 13061311. doi:10.1016/s1872-2067(11)60410-5

Vishwakarma, K., Shweta, Upadhyay, N., Singh, J., Liu, S., Singh, V.P., Prasad, S.M., Chauhan D.K., Tripathi D., Sharma, S. (2017). Differential phytotoxic impact of plant mediated silver nanoparticles (AgNPs) and silver nitrate (AgNO3) on Brassica sp. Frontiers in Plant Science, 8. doi:10.3389/fpls.2017.01501

Yan, A., Chen, Z. (2019). Impacts of silver nanoparticles on plants: a focus on the phytotoxicity and underlying mechanism. International Journal of Molecular Sciences, 20(5), 1003. doi:10.3390/ijms20051003

Zaka, M., Abbasi, B.H. (2017). Effects of bimetallic nanoparticles on seed germination frequency and biochemical characterisation of Eruca sativa. IET Nanobiotechnology, 11(3), 255-260. doi:10.1049/iet-nbt.2016.0004

Zhang, W.-Y., Wang, Q., Li, M., Dang, F., Zhou, D.-M. (2019). Nonselective uptake of silver and gold nanoparticles by wheat. Nanotoxicology, 1-26. doi:10.1080/17435390.2019.1640909 